\title{
Response
}

\section{Association of Thigh Muscle Mass with Insulin Resistance and Incident Type 2 Diabetes Mellitus in Japanese Americans (Diabetes Metab J 2018;42:488-95)}

\author{
Seung Jin Han $^{1}$, Edward J. Boyko ${ }^{2}$ \\ ${ }^{1}$ Department of Endocrinology and Metabolism, Ajou University School of Medicine, Suwon, Korea, \\ ${ }^{2}$ Seattle Epidemiologic Research and Information Center, VA Puget Sound Health Care System, Seattle, WA, USA
}

We thank Dr. Kim for expressing interest and giving comments on our article entitled "Association of thigh muscle mass with insulin resistance and incident type 2 diabetes mellitus in Japanese Americans" which was published in Diabetes \& $M e-$ tabolism Journal [1].

We agree with Dr. Kim's suggestion of the potential value of measurement of thigh intramuscular or intermuscular fat content. However, these measurements were not available for this study. Previous studies demonstrated that fat in these areas was significantly associated with insulin resistance and the development of type 2 diabetes mellitus (T2DM) [2-4]. Although fat infiltrated in muscle accounts for a relatively small portion of the total skeletal muscle, it may be important in the development of T2DM apart from muscle mass [4,5].

In response to your question about whether we have investigated the relationship between abdominal fat distribution and thigh muscle mass, we have done so and will present the results here. The correlation between thigh muscle mass area and intra-abdominal fat area was $-0.007(P=0.923$ in men) and -0.064 ( $P=0.380$ in women) and between thigh muscle mass area and subcutaneous abdominal fat area $0.197(P=0.005$ in men) and 0.123 ( $P=0.089$ in women). As the subcutaneous fat depot represents the largest adipose depot in the body, we believe that its positive correlation with thigh muscle reflects the previously observed correlation between overall adiposity as measured by body mass index (BMI) and muscle mass [6]. In- deed, after adjustment of the association between thigh muscle area and subcutaneous abdominal fat area for BMI, there was a significant negative association apparent in men and women. In the current study, thigh muscle area was inversely associated with insulin resistance independent of total abdominal fat area. An interaction between thigh muscle mass area and BMI in relation to T2DM was also observed after adjusting for total abdominal fat area.

Thank you again for your interest in our research and your thoughtful comments.

\section{CONFLICTS OF INTEREST}

No potential conflict of interest relevant to this article was reported.

\section{REFERENCES}

1. Han SJ, Boyko EJ, Kim SK, Fujimoto WY, Kahn SE, Leonetti DL. Association of thigh muscle mass with insulin resistance and incident type 2 diabetes mellitus in Japanese Americans. Diabetes Metab J 2018;42:488-95.

2. Kim SK, Park SW, Hwang IJ, Lee YK, Cho YW. High fat stores in ectopic compartments in men with newly diagnosed type 2 diabetes: an anthropometric determinant of carotid atherosclerosis and insulin resistance. Int J Obes (Lond) 2010;34:105-10.
Corresponding author: Seung Jin Han (D) https://orcid.org/0000-0003-4783-6799 Department of Endocrinology and Metabolism, Ajou University School of Medicine, 164 World cup-ro, Yeongtong-gu, Suwon 16499, Korea

E-mail: hsj@ajou.ac.kr
This is an Open Access article distributed under the terms of the Creative Commons Attribution Non-Commercial License (http://creativecommons.org/licenses/by-nc/4.0/) which permits unrestricted non-commercial use, distribution, and reproduction in any medium, provided the original work is properly cited. 
3. Kim D, Nam S, Ahn C, Kim K, Yoon S, Kim J, Cha B, Lim S, Kim K, Lee H, Huh K. Correlation between midthigh lowdensity muscle and insulin resistance in obese nondiabetic patients in Korea. Diabetes Care 2003;26:1825-30.

4. Goodpaster BH, Thaete FL, Kelley DE. Thigh adipose tissue distribution is associated with insulin resistance in obesity and in type 2 diabetes mellitus. Am J Clin Nutr 2000;71:885-92.
5. Stump CS, Henriksen EJ, Wei Y, Sowers JR. The metabolic syndrome: role of skeletal muscle metabolism. Ann Med 2006;38: 389-402.

6. Gasier HG, Hughes LM, Young CR, Richardson AM. Comparison of body composition assessed by dual-energy X-ray absorptiometry and $\mathrm{BMI}$ in current and former U.S. navy service members. PLoS One 2015;10:e0132157. 